\title{
COMPUTATIONAL APPROACHES OF NEW PERSPECTIVES IN THE TREATMENT OF DEPRESSION DURING PREGNANCY
}

\author{
ANA-MARIA UDREA ${ }^{1}$, ALIN PUIA $^{1} *$, SERGEY SHAPOSHNIKOV ${ }^{2}$, SPERANȚA AVRAM $^{1}$ \\ ${ }^{1}$ Department of Anatomy, Animal Physiology and Biophysics, Faculty of Biology, University of Bucharest, 91-95 Splaiul \\ Independenței Street, 050095, Bucharest, Romania \\ ${ }^{2}$ Norgenotech AS, 21 Gaustadalleen Street, 0349, Oslo, Norway \\ *corresponding author: alinro_90@yahoo.com
}

Manuscript received: April 2018

\begin{abstract}
Antidepressants and antipsychotics are drugs used in the treatment of neuropsychiatric disorders, but because they have side effects on new-borns their use is not recommended during pregnancy. Natural compounds represent an innovative opportunity for the management of depression, but the molecular mechanisms on brain membrane receptors are unknown. Our aims are to predict the binding affinities of melatonin, resveratrol, linalool and linalyl acetate at SERT (serotonin transporter), deeply involved in neuropsychiatric disorders mechanisms, their drug likeness, pharmacokinetics features and the transfer index (TI) through placenta by using QSAR (Quantitative Structure-Activity Relationship) and in silico ADMET (Absorption Distribution Metabolism Excretion Toxicity) techniques. Our study concluded that natural compounds represent promising drug candidates in the treatment of depression.
\end{abstract}

\section{Rezumat}

Antidepresivele și antipsihoticele sunt medicamente utilizate în tratamentul patologiilor neuropsihiatrice, dar din cauza efectelor negative asupra nou-născuților, acestea nu sunt recomandate utilizării pe parcursul sarcinii. Compuşii naturali reprezintă o alternativă promițătoare în tratamentul depresiei, dar mecanismul molecular al acestora asupra receptorilor membranari din creier este necunoscut. Scopul acestui studiu este de a evalua activitatea biologică a melatoninei, resveratrolului, acetatului de linalil şi linalol asupra transportorului de serotonina (implicat în mecanismul patologiilor psihiatrice), caracterul de medicament, caracteristicile farmacocinetice și indicele de transfer (IT) placentar, utilizând tehnicile QSAR și ADMET in silico. Acest studiu a arătat că acești compuși naturali reprezintă candidați promițători pentru tratamentul depresiei.

Keywords: QSAR, pregnancy, resveratrol, lavender, melatonin

\section{Introduction}

Medications used in treatment of depression during pregnancy have side effects in foetal, development. Natural compounds represent a suitable treatment for neuropsychiatric disorders.

In this paper we calculated (i) the inhibition constant on serotonin transporter of natural compounds, noninvasive in foetal development, to predict the antidepressant activity of them; (ii) the placental transfer index permeability for natural compounds, antipsychotics and antidepressant drugs.

Pregnancy is a time of great changes for women's body and unfortunately, some women are suffering from depression, an illness that affects $8.3-12 \%$ of pregnant women in America [9]. Generally, the best results in the treatment of depression are obtained when psychotherapy is combined with antidepressant drugs [11]. However, usage of these drugs in pregnancy may cause changes in foetal development, shorter duration of gestation [18, 30, $31]$ and in the first trimester of gestation may also result in foetal malformations [31]. In these cases, the new-borns might present: low weight, small head circumference, lower Apgar scores, neonatal irritability and behavioural changes [18, 30, 31]. For the reasons presented above, the use of antidepressant drugs is not recommended and natural alternatives are demanded.

There are several classes of antidepressants divided by mechanism of action: serotonin-norepinephrine reuptake inhibitors, noradrenergic and specific serotonergic antidepressant, selective serotonin reuptake inhibitors, tricyclic antidepressants, tetracyclic anti-depressants and monoamine oxidase inhibitors [15, 32]. Majority of the classes of antidepressant drugs have SERT as main target $[3,8,13]$.

In the current study we have predicted the biological activity of 4 plant extracts: melatonin extract from Goji fruit (Lycium barbarum L. and Lycium chinense Mill.), resveratrol extract from red wine [5], as well as linalool and linalyl acetate extracts from lavender (Lavandula angustifolia Mill.). In order to find their similar antidepressant effects with classical medication. It was recently mentioned that melatonin and resveratrol do not present negative effects on new-borns $[17,25]$, 
while the data about linalool and linalyl acetate on new-borns is not available yet.

Melatonin (N-acetyl-5methoxytryptamine) is an indole produced by the pineal gland, with essential physiological roles (sleep, detoxification of free radicals, cancer inhibition, etc.). Melatonin and its derivatives have positive effects in major depressive disorder by regulating the circadian rhythm and improving sleep quality. Melatonin is a melatoninergic1 and melatoninergic2 receptors agonist and 5- $\mathrm{HT}_{2 \mathrm{C}}$ antagonist [24]. Resveratrol (trans-3,5,4'-trihydroxy-trans-stilbene, RES) is a polyphenol that is found in blue berries (Vaccinium myrtillus L.) and red wine with benefits in the management or prevention of numerous illnesses such as: diabetes, brain disease, inflammation, circulator system diseases, cancer etc. [2, 14, 29]. New studies show that resveratrol could have antidepressant-like effects in rat models [7].

Linalyl acetate and linalool are the main constituents of silexan (70 - 80\%). Silexan is a capsule with lavender essential oil, used in the treatment of generalized anxiety disorder [12]. However, the mechanism of action of silexan is still unclear. The mechanism of action of these natural compounds on neuropsychiatric disorders as well as the quantification of their biological activities (expressed as inhibition constants $\left(\mathrm{K}_{\mathrm{i}}\right)$ ) on membrane receptors (e.g. SERT), is not known.

Therefore, here we predicted the biological activities of melatonin, resveratrol linalool and linalyl acetate expressed as inhibition constant, $\mathrm{K}_{\mathrm{i}}$ on SERT receptor by used computational methods (QSAR) and we computed their pharmacokinetic profiles (ADMET). An important factor in the safety profile of using drugs during pregnancy is to know whether they are penetrating the placenta, which is measured using the transfer index (TI) [10]:

$\mathrm{TI}=$ Transfer of drug / transfer of antipyrene.

A TI of 1.24 or higher indicates a full transfer has occurred [10]. These data are not available for a large number of drugs and natural compounds. For antidepressant drugs TI of only the following compounds is available 4: amitriptyline (0.81), citalopram (0.86), fluoxetine (0.88), nortriptyline (0.62) and melatonin (0.93) [10]. We have computed TI for melatonin, resveratrol, linalool and linalyl acetate, as well as for many other antidepressants and antipsychotic drugs. Our findings suggest that computational methods presented here can contribute to find an optimal treatment of depression in groups of individuals with risk factors.

\section{Materials and Methods}

\section{Molecular database}

For our QSAR models we have selected (i) a set of 15 antidepressants (amitriptyline, amoxapine, citalopram, desipramine, escitalopram, femoxetine, fluoxetine, fluvoxamine, indalpine, lofepramine, norfluoxetine, nortriptyline, reboxetine, trazodone, venlafaxine) and 8 antipsychotic drugs (amisulpride, aripiprazole, chlorpromazine, clozapine, quetiapine, risperidone, sertindole, ziprasidone) clinically used in the treatment of depression with known $\mathrm{K}_{\mathrm{i}}(\mathrm{uM})$ on SERT membrane receptor from PDSP $\mathrm{K}_{\mathrm{i}}$ database [21]. Biological activity, $\mathrm{K}_{\mathrm{i}}(\mathrm{M})$, was expressed as $\mathrm{pK}_{\mathrm{i}}$ applying the logarithm function: $\log ((1 / \mathrm{Ki}) \mathrm{M})$, (ii) 31 drugs: antibiotics (amoxicillin, ciprofloxacin, ofloxacin, levofloxacin); analgesics and anaesthetics (antipyrine, lidocaine, methohexital, paracetamol); drugs used in type II diabetes (chlorpropamide, glipizide, glyburide tolbutamide); hypertension and attention deficit hyperactivity disorder (clonidine); anxiety reducing drugs (dexmedetomidine, diazepam, nordiazepam, sulpirid); drugs used in stomach ulcers treatment (famotidine, nizatidine, pirenzepine, ranitidine); drug used in bipolar disorder treatment (lamotrigine); anti-inflammatory drugs (oxyphenbutazone, phenylbutazone); drugs used in the treatment of respiratory diseases (clenbuterol, ambroxol) antidepressants (amitryptiline, fluoxetine, citalopram, nortriptyline) and natural compound (melatonin) with known TI values from literature [10].

Molecular modelling and minimum energy optimization To investigate the biological activity of natural compounds: melatonin, resveratrol, linalool and linalyl acetate on SERT and TI we acquired the 3D structures of antidepressant, antipsychotic drugs and natural compounds in format .mol from CHEMBL database [26]. We used Molecular Operating Environment 10 (MOE.10) software [19] to minimize the potential energy of the structures. The energy of structures was minimized using Forcefield MMFF94x at a 0.05 gradient; after minimization, Gasteiger partial charges were applied for all molecules [6].

QSAR Protocols

\section{Molecular descriptors}

After minimization protocol we calculated 200 (2D and 3D) molecular descriptors for each compound, using MOE software (ex: flexibility, energy of torsion, $\log \mathrm{P}(\mathrm{o} / \mathrm{w})$ (Log octanol/water partition coefficient), SMR (Molar Refractivity) etc. Then we calculated the correlation between the molecular descriptors for the use in QSAR modelling: only correlations lower than 0.8 were accepted. In each QSAR model from all the molecular descriptors we have selected three molecular descriptors that are not correlated and with relevance in drug-likeness. Pearson correlation matrix: highest correlation is between E_vdw and SMR 0.751; lowest correlation is between SMR and $\operatorname{LogP}$ of 0.126 ; $\mathrm{QSAR}_{\mathrm{TI}}$ : Pearson correlation matrix highest correlation is between a_don and $\operatorname{LogP}$ at -0.534 ; lowest correlation is between a_don and SMR. In both cases we don't have a correlation higher than 0.8 , which means that these descriptors could be used in QSAR model (Table I). 
Pearson correlation matrix of descriptors used in both QSAR models

\begin{tabular}{llllllll}
\hline QSAR $_{\text {SERT }}$ : Pearson correlation matrix. & \multicolumn{5}{c}{ QSAR $_{\mathrm{TI}}$ : Pearson correlation matrix. } \\
\hline & SMR & $\operatorname{LogP}$ & E_vdw & & $\operatorname{LogP}$ & a_don & SMR \\
\hline SMR & 1 & & & LogP & 1 & & \\
\hline LogP & 0.126 & 1 & & a_don & -0.534 & 1 & \\
\hline E_vdw & 0.751 & 0.383 & 1 & SMR & 0.152 & 0.115 & 1 \\
\hline
\end{tabular}

In QSAR SERT model we have selected: $\operatorname{LogP}(\mathrm{o} / \mathrm{w})$, SMR, Van der Waals energy (E_vdw). The QSAR equation for this model is:

$$
S E R T=10.50183-0.03615 \times E_{v d w}-0.42259 \times S M R+0.79453 \times \log P
$$

In $\mathrm{QSAR}_{\mathrm{TI}}$ model we have selected: $\operatorname{LogP}(\mathrm{o} / \mathrm{w}), \mathrm{SMR}$ and Number of $\mathrm{H}$-bond donor atoms (a_don). QSAR equation for this model is:

$$
T I=1.68607-0.05682 \times a_{d o n}+0.07859 \times \log P-0.13854 \times S M R
$$

$\log P$ has a significant role in how a drug reaches the desired target and how fast it undergoes the procedure required for the specific activity. It also influences the intensity of the positive effect; and the period that the active form of the drug remains in the body [6]. E_vdw represents the Van der Waals component of potential energy and H-bond donor atoms number influences the water solubility of a molecule. A large number of a_don indicates low fat solubility, so the drug is unable to penetrate the cellular membrane [16].

Chemometric analysis

A strong prediction power of a QSAR model is dictated by a reliable equation for structure activity relationship and should be characterized by: good correlation coefficients $\left(\mathrm{R}^{2}\right)$, (higher than 0.800 ), a low standard error of prediction (smaller than 0.400 ), Cross-validated R2 $\left(\mathrm{q}^{2}\right)$ (needs to exceed 0.700) and a low Cross-validated Root mean Square Deviation value (lower than 0.5) [20]. Regression analysis was executed using the Partial Least Squares algorithm in MOE 10 software. We selected three principal components to achieve ideal values for statistical parameters $\mathrm{q}^{2}$ and $\mathrm{R}^{2}$, which were evaluated by executing the cross-validation and respectively non-cross-validated processes existing in MOE 10 software.

\section{Learning, validation and test set}

Using our computational expertise $[1,28]$ we build 2 QSAR models to achieve our goal: QSAR model 1 $\left(\mathrm{QSAR}_{\mathrm{SERT}}\right)-\mathrm{pK}_{\mathrm{i}}$ prediction on SERT of natural compounds to predict the antidepressant-like activity of natural compounds, and QSAR model $2\left(\mathrm{QSAR}_{\mathrm{TI}}\right)$ prediction of TI for antipsychotics, antidepressants and natural compounds with possible antidepressant effect, to predict the safety of using antidepressants, antipsychotics and natural compounds in pregnancy. After selection of descriptors, we randomly divided the molecules in learning and validation set. In QSAR SERT $_{\text {S }}$ model we have 19 molecules in learning set and 4 (amisulpride, clozapine, nortriptiline and sertindole) in validation set.

In QSAR $_{\mathrm{TI}}$ model we used 26 molecules in learning set and 5 molecules in validation set (chlorpropamide, famotidine, glipizide, tolbutamide and lidocaine). The prediction power of our QSAR models is confirmed by our statistical parameters (Table II): Root mean Square Deviation, $\mathrm{R}^{2}$, Cross-validated Root mean Square Deviation and $\mathrm{q}^{2}$. The QSAR equation from QSAR SERT $_{\text {S }}$ was applied to molecules from test set. In test set we have 4 molecules from plants (resveratrol, melatonin linalool and linalyl acetate) with possible antidepressant activity. The QSAR equation from $\mathrm{QSAR}_{\mathrm{TI}}$ was applied to molecules from the test set. In this case the test set had 42 molecules: antidepressants (19) antipsychotics (18) and the natural compounds (4 molecules).

Table II

Statistical parameters for both QSAR models

\begin{tabular}{lll}
\hline Statistical parameters & QSAR $_{\text {SERT }}$ & QSAR $_{\mathrm{TI}}$ \\
\hline Root mean Square Deviation & 0.33 & 0.089 \\
\hline $\mathrm{R}^{2}$ & 0.90 & 0.89 \\
\hline Cross-Validated Root mean Square Deviation & 0.42 & 0.10 \\
\hline $\mathrm{q}^{2}$ & 0.84 & 0.85 \\
\hline
\end{tabular}

Evaluation of drug-likeness profile (Lipinski's rule of five)

Analysis of drug-likeness of the new compounds was done by applying the Lipinski's rule of five referring at the possibility of drug-like action of small molecules if the following criteria are respected: no more than five a_don, no more than ten number of $\mathrm{H}$-bond acceptors (a_acc), a LogP smaller than five, and an MW smaller than 500 Daltons [16]. Here we applied the rule of five to the natural compounds resveratrol 
FARMACIA, 2018, Vol. 66, 4

$\left(\log \mathrm{P}=3.69\right.$; $\mathrm{a} \_\mathrm{acc}=3 ; \mathrm{a} \_$don $\left.=3 ; \mathrm{MW}=228.24\right)$, linalyl acetate $(\operatorname{LogP}=2.71$; a_acc $=1$; a_don $=0$; $\mathrm{MW}=196.29)$, melatonin $\left(\log \mathrm{P}=1.77\right.$; $\mathrm{a} \_\mathrm{acc}=2$; a_don $=2 ; \mathrm{MW}=232.28)$ and linalool $(\log \mathrm{P}=2.13$; a_acc $=1 ;$ a_don $=1 ; \mathrm{MW}=154.25)$. We correlated our results with other available information in different bioinformatics database Pubchem database [27]: resveratrol $(\mathrm{X} \operatorname{LogP} 3=3.1$; a_acc $=3$; a_don $=3$; $\mathrm{MW}=228.24)$, linalyl acetate $\left(\mathrm{X} \log \mathrm{P} 3=3.3\right.$; $\mathrm{a} \_\mathrm{acc}=2$; a $\operatorname{don}=0 ; \mathrm{MW}=196.29)$ melatonin $(\mathrm{X} \log \bar{P} 3=0.8$; a_acc $=2 ;$ a_don $=2 ; \mathrm{MW}=232.28)$ and linalool $\left(\mathrm{XLogP} 3=2.7 ; \mathrm{a} \_\right.$acc $=1 ; \mathrm{a} \_$don $\left.=1 ; \mathrm{MW}=154.25\right)$. All the natural compounds respect Lipinski's rule and may have drug-like effect.

\section{In silico ADMET methods}

In silico ADMET studies are a valuable tool in Drug discovery. Here we have tested natural compounds (melatonin, linalool, linalyl acetate and resveratrol) and fluoxetine, which is one of the most used drugs in depression treatment. All these compounds have similar $\mathrm{pK}_{\mathrm{i}}$ value on SERT. The ADMET study was running in pkCSM platform [23], the SMILES structure of the drug and natural compounds was taken from Drug Bank database [4].

We have chosen PkCSM platform based on high statistical values of predictions for selected functions: intestinal absorption $\left(\mathrm{R}^{2}=0.902\right)$, Steady-state Volume

of Distribution (VDss) $\left(\mathrm{R}^{2}=0.702\right)$, fraction unbound $\left(\mathrm{R}^{2}=0.862\right)$, Blood-Brain-Barrier $(\mathrm{BBB})$ permeability $\left(\mathrm{R}^{2}=0.862\right)$, total clearance $\left(\mathrm{R}^{2}=0.755\right)$ and rat Lethal Dose (LD) $50\left(R^{2}=0.779\right)$ [22].

\section{Results and Discussion}

$Q S A R_{S E R T}$

Running the QSAR ${ }_{\text {SERT }}$ model equation we obtained suitable statistical results $\left(\mathrm{R}^{2}=0.90 \mathrm{q}^{2}=0.84\right)$ for learning set the best residual value is 0.04 while the worst was -0.56 . The power of prediction of our QSAR model is confirmed by the value of residuals between experimental and predicted. Results show that the natural compounds and antidepressant drugs have similar pKi activity on SERT.

$\mathrm{PK}_{\mathrm{i}}$ of antidepressants on SERT have a range between 6.79 (trazodone) and 9.09 (fluoxetine). The natural compounds have $\mathrm{pK}_{\mathrm{i}}$ values from 8.17 (melatonin) to 9.67 (linalool) (Table III); The predicted $\mathrm{pK}_{\mathrm{i}}$ value of melatonin (8.17) is close to the $\mathrm{pK}_{\mathrm{i}}$ value of venlafaxine; resveratrol (9.30), linalool (9.67) and linalyl acetate $(9.48)$ predicted $\mathrm{pK}_{\mathrm{i}}$ values are close to $\mathrm{pK}_{\mathrm{i}}$ value of fluoxetine (Table III). The close $\mathrm{pK}_{\mathrm{i}}$ value of natural compounds with fluoxetine and venlafaxine indicate similar activity on the receptor. Fluoxetine is one of the most used drugs in the treatment of depression.

Table III

Experimental $\mathrm{pK}_{\mathrm{i}}$, predicted $\mathrm{pK}_{\mathrm{i}}$ on SERT, and residuals. Underlined molecules represent the training set. Bolded natural compounds.

\begin{tabular}{llll}
\hline Molecule & SERT-experimental $\mathrm{pK}_{\mathrm{i}}$ & SERT- predicted $\mathrm{pK}_{\mathrm{i}}$ & Residual \\
\hline Amisulpride & $\underline{5.00}$ & $\underline{5.90}$ & -0.90 \\
\hline Amitriptyline & 8.55 & 8.51 & 0.04 \\
\hline Amoxapine & 7.20 & 7.38 & -0.18 \\
\hline Aripiprazole & 5.74 & 6.34 & -0.60 \\
\hline Chlorpromazine & 8.88 & 8.44 & 0.44 \\
\hline Citalopram & 8.94 & 8.56 & 0.38 \\
\hline Clozapine & $\underline{6.00}$ & $\underline{7.00}$ & -1.00 \\
\hline Desipramine & 7.75 & 8.16 & -0.41 \\
\hline Escitalopram & 8.95 & 8.58 & 0.37 \\
\hline Femoxetine & 7.95 & 7.66 & 0.29 \\
\hline Fluoxetine & 9.09 & 9.46 & -0.37 \\
\hline Fluvoxamine & 8.79 & 8.64 & 0.15 \\
\hline Indalpine & 8.76 & 9.26 & -0.50 \\
\hline Lofepramine & 7.15 & 7.29 & -0.14 \\
\hline Norfluoxetine & 8.83 & 8.67 & 0.16 \\
\hline Nortriptiline & $\underline{7.82}$ & $\underline{8.67}$ & -0.85 \\
\hline Quetiapine & 6.00 & 5.90 & 0.10 \\
\hline Reboxetine & 6.97 & 7.53 & -0.56 \\
\hline Risperidone & 6.00 & 6.04 & -0.04 \\
\hline Sertindole & $\underline{6.00}$ & $\underline{6.96}$ & -0.96 \\
\hline Trazodone & 6.79 & 6.40 & 0.39 \\
\hline Venlaflaxine & 8.12 & 7.86 & 0.26 \\
\hline Ziprasidone & 7.27 & 7.06 & 0.21 \\
\hline Resveratrol & - & $\mathbf{9 . 3 0}$ & - \\
\hline Linalyl acetate & - & $\mathbf{9 . 4 8}$ & - \\
\hline Melatonin & - & $\mathbf{8 . 1 7}$ & - \\
\hline Linalool & - & $\mathbf{9 . 6 7}$ & \\
\hline & & & - \\
\hline
\end{tabular}


FARMACIA, 2018, Vol. 66, 4

$Q S A R_{T I}$

Running the $\mathrm{QSAR}_{\mathrm{TI}}$ model equation we obtained suitable statistical results $\left(\mathrm{R}^{2}=0.89 \mathrm{q}^{2}=0.85\right)$. For learning set the best residual value was 0.006 , and the worst was -0.16 . The power of prediction of our QSAR model is confirmed by the value of residuals between experimental and predicted. Results show that antidepressants have TI values from 0.66 (amoxepine) to 0.96 (bupropion); antipsychotics have TI values from 0.27 (aripiprazole) to 0.79 (promazine), and natural compounds are within a range from 0.90 to 1.12 (Table IV).

Table IV

Observed TI, predicted TI and residuals underlined molecules represent the training set. Bolded: antidepressants, antipsychotics and natural compounds.

\begin{tabular}{|c|c|c|c|c|c|}
\hline Molecule & TI & Predicted TI & Residual & Molecule & Predicted TI \\
\hline Amitriptyline & 0.81 & 0.80 & 0.006 & Clozapine & 0.59 \\
\hline Amoxicillin & 0.15 & 0.17 & -0.02 & Desipramine & 0.76 \\
\hline Antipyrine & 1 & 1.02 & -0.02 & Doxepine & 0.80 \\
\hline Chlorpropamide & $\underline{0.5}$ & $\underline{0.78}$ & $\underline{-0.28}$ & Duloxetine & 0.72 \\
\hline Ciprofloxacin & 0.34 & 0.41 & -0.07 & Escitalopram & 0.72 \\
\hline Citalopram & 0.86 & 0.72 & 0.13 & Femoxetine & 0.67 \\
\hline Clonidine & 1.04 & 0.97 & 0.06 & Fluphenazine & 0.33 \\
\hline Dexmedetomidine & 0.88 & 0.90 & -0.02 & Fluvoxamine & 0.77 \\
\hline Diazepam & 0.85 & 0.81 & 0.03 & Haloperidol & 0.55 \\
\hline Famotidine & $\underline{0.84}$ & $\underline{0.19}$ & $\underline{0.64}$ & Iloperidone & 0.36 \\
\hline Fluoxetine & 0.88 & 0.86 & 0.01 & Imipramine & 0.78 \\
\hline Glipizide & $\underline{0.3}$ & $\underline{-0.01}$ & $\underline{0.31}$ & Indalpine & 0.85 \\
\hline Glyburide & $\overline{0.13}$ & $\overline{0.04}$ & $\overline{0.08}$ & Iprindole & 0.82 \\
\hline Lamotrigine & 1.06 & 0.91 & 0.14 & Lofepramine & 0.43 \\
\hline Levofloxacin & 0.33 & 0.35 & -0.02 & Loxapine & 0.67 \\
\hline$\underline{\text { Lidocaine }}$ & $\underline{0.59}$ & $\underline{0.81}$ & $\underline{-0.22}$ & Mesoridazine & 0.43 \\
\hline Melatonin & 0.93 & 0.78 & 0.14 & Mianserin & 0.81 \\
\hline Methohexital & 0.87 & 0.76 & 0.10 & Norfluoxetine & 0.78 \\
\hline Ambroxol & 0.58 & 0.69 & -0.11 & Olanzapine & 0.57 \\
\hline Nizatidine & 0.4 & 0.43 & -0.03 & Paroxetine & 0.64 \\
\hline Nordiazepam & 0.84 & 0.80 & 0.03 & Prochlorperazine & 0.53 \\
\hline Nortriptyline & 0.62 & 0.78 & -0.16 & Promazine & 0.79 \\
\hline Ofloxacin & 0.34 & 0.35 & -0.01 & Quetiapine & 0.30 \\
\hline Oxiphenbutazone & 0.51 & 0.64 & -0.13 & Remoxipride & 0.59 \\
\hline Paracetamol & 0.92 & 1.05 & -0.13 & Risperidone & 0.33 \\
\hline Phenylbutazone & 0.61 & 0.74 & -0.13 & Sertindole & 0.29 \\
\hline Pirenzepine & 0.35 & 0.31 & 0.03 & Sertraline & 0.86 \\
\hline Ranitidine & 0.44 & 0.48 & -0.04 & Thioridazine & 0.60 \\
\hline Clenbuterol & 0.85 & 0.74 & 0.10 & Trifluoperazine & 0.54 \\
\hline Sulpirid & 0.41 & 0.38 & 0.02 & Agomelatine & 0.82 \\
\hline$\underline{\text { Tolbutamide }}$ & $\underline{1.12}$ & $\underline{0.73}$ & $\underline{0.38}$ & Venlafaxine & 0.73 \\
\hline Amoxepine & - & 0.66 & - & Ziprasidone & 0.35 \\
\hline Aripiprazole & - & 0.27 & - & Linalyl Acetate & 1.07 \\
\hline Bupropion & - & 0.96 & - & Resveratrol & 0.90 \\
\hline Chlorpromazine & - & 0.77 & - & Linalool & 1.12 \\
\hline Clomipramine & - & 0.76 & - & - & - \\
\hline
\end{tabular}

High values of TI of antidepressants indicate their ability to cross the placental barrier and are thus unsafe to use in the treatment of depression in pregnancy $[15,31,32]$.

All the natural compounds have TI values indicating that they cross the placental barrier, however in accordance with studies $[17,25]$ melatonin and resveratrol are safe to use despite of the fact that they cross the barrier. We were not able to collect safety data on the use of linalool and linalyl acetate during pregnancy. Linalool have the same TI value with tolbutamide (1.12), resveratrol TI value (0.90) is similar with the value of paracetamol (0.92), and linalyl acetate TI value (1.07) is similar with the value of lamotrigine (1.06).

TI of antipsychotic drugs indicates that this class of drugs has a poor ability in crossing the placental barrier, which indicates that they are safe to use during pregnancy. Aripiprazole is the antipsychotic drug with the lowest TI value $(0.27)$, similar with the value of glipizide (0.30) - a drug used in the treatment of type II diabetes. Promazine is the antipsychotic drug that has the highest TI value (0.79), which indicates that this drug has a high placental permeability (similar with the value of amitriptyline). QSAR models are sustained by the correlation between predicted and experimental values of molecules (Figure 1). 

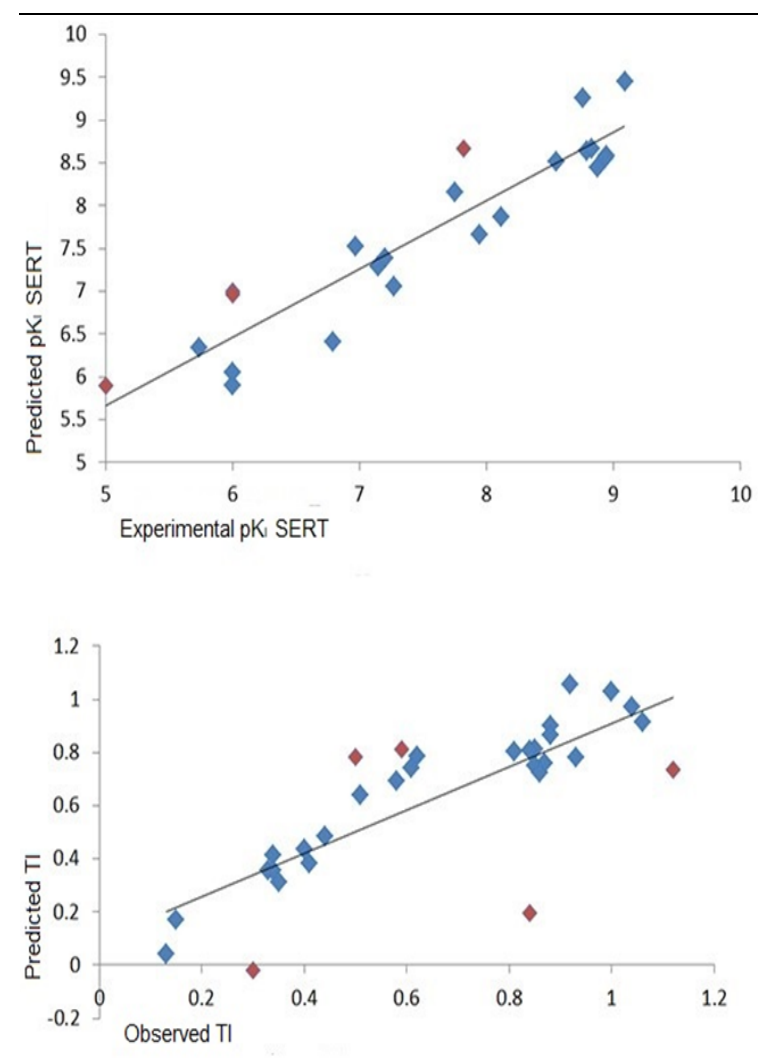

Validation set

$\checkmark$ Learning set

\section{Figure 1.}

Comparison between experimental and predicted $\mathrm{pK}_{\mathrm{i}}$ values of antidepressant and antipsychotic drugs on $\mathrm{QSAR}_{\mathrm{SERT}}$ model and $\mathrm{QSAR}_{\mathrm{TI}}$ model

\section{In silico ADMET}

Results of the ADMET study (Table V) show that unlike fluoxetine, the studied natural compounds have no hepatotoxicity; the studied natural compounds and fluoxetine have a high intestinal absorption (IA); fluoxetine has a high VDss, whereas the natural compounds have medium.

The more parts of the drug are bound the less efficient is its ability to penetrate the membranes and diffuse. The number of unbound molecules in the case of natural compounds is much lower than in the case of fluoxetine, which indicates that their efficiency is much higher.

(v) $\mathrm{BBB}$ permeability refers to the ability of a drug to cross the $\mathrm{BBB}$ : if a compound has a $\log \mathrm{BBB}>0.3$ it crosses the $\mathrm{BBB}$, whereas molecules with $\log \mathrm{BBB}<-1$ have a poor capacity in crossing the BBB. Our results have shown that fluoxetine, linalyl acetate and linalool crosses the BBB with a similar permeability, whereas melatonin and resveratrol presented the poor capacity of crossing BBB. (vi) Total clearance (the renal and hepatic clearance of a drug) is similar for fluoxetine, linalool and melatonin, higher for linalyl acetate, and lower for resveratrol. (vii) The rat oral $\mathrm{LD}_{50}$ (the dose that causes death to $50 \%$ of rats) for fluoxetine, resveratrol and melatonin is higher than $\mathrm{LD}_{50}$ of linalool and linalyl acetate (Table $\mathrm{V}$ and Figure 2).

\begin{tabular}{|c|c|c|c|c|c|c|}
\hline \multirow[t]{2}{*}{ Model } & \multicolumn{5}{|c|}{ Predicted values for } & \multirow[t]{2}{*}{ Unit } \\
\hline & resveratrol & melatonin & linalyl acetate & linalool & fluoxetine & \\
\hline $\begin{array}{l}\text { Intestinal Absorption } \\
\text { (human) }\end{array}$ & 90.935 & 94.164 & 95.275 & 93.163 & 91.813 & $\begin{array}{l}\text { \% Absorbed } \\
(>30 \%=\text { poorly absorbed) }\end{array}$ \\
\hline VDss (human) & 0.296 & 0.082 & 0.069 & 0.152 & 1.058 & $\begin{array}{l}\log \mathrm{L} / \mathrm{kg} \\
(\operatorname{low}-0.15>\log \text { Dss }>0.45 \text { high })\end{array}$ \\
\hline $\begin{array}{l}\text { Fraction unbound } \\
\text { (human) }\end{array}$ & 0.166 & 0.289 & 0.423 & 0.484 & 0.039 & $\begin{array}{l}\text { Fu (higher fraction unbound more } \\
\text { efficient drug) }\end{array}$ \\
\hline BBB permeability & -0.048 & -0.076 & 0.516 & 0.598 & 0.505 & $\begin{array}{l}\log \mathrm{BBB} \text { (poorly cross }-1>\log \mathrm{BBB} \\
>0.3 \text { crosses) }\end{array}$ \\
\hline Total Clearance & 0.076 & 0.735 & 1.627 & 0.446 & 0.68 & $\log \mathrm{mL} / \mathrm{min} / \mathrm{kg}$ \\
\hline Rat $\left(\mathrm{LD}_{50}\right)$ & 2.529 & 2.159 & 1.729 & 1.704 & 2.849 & $\mathrm{~mol} / \mathrm{kg}$ \\
\hline Hepatotoxicity & No & No & No & No & Yes & Yes/No \\
\hline
\end{tabular}




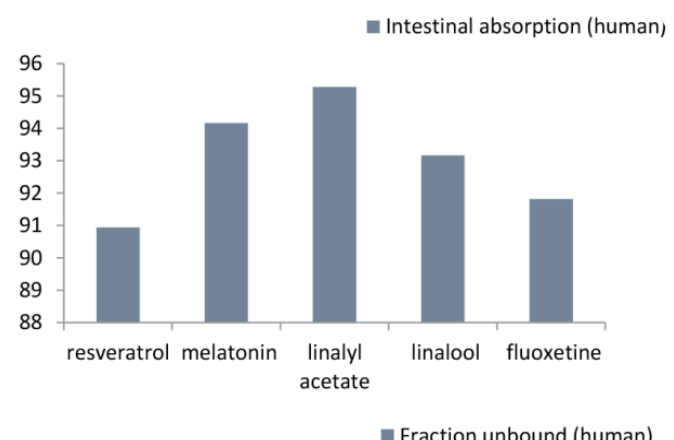

VDss (human)
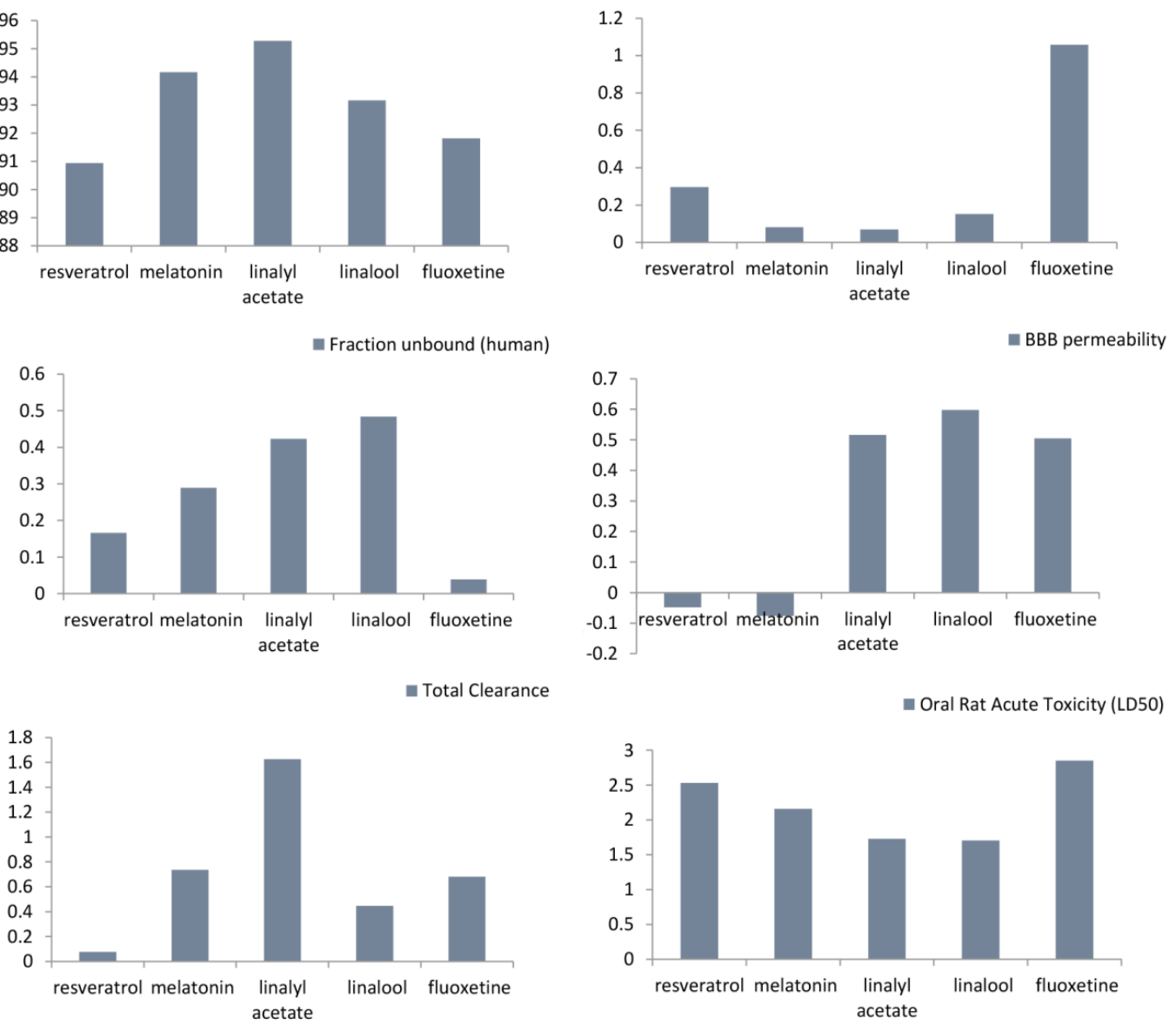

Figure 2.

In silico ADMET graphical representation of predicted values belonging to natural compounds and fluoxetine

\section{Conclusions}

Our study concludes that (i) natural compounds melatonin, resveratrol, linalool and linalyl acetate could be a good alternative in treatment of depression. Their $\mathrm{pK}_{\mathrm{i}}$ on SERT receptor is similar to the $\mathrm{pK}_{\mathrm{i}}$ of classical medications. Linalyl acetate and linalool are the main constituents of a product already used as treatment for anxiety: silexan. (ii) All antidepressants drugs and natural compounds studied have TI values indicating that they do cross the placental barrier, whereas the TI values of the studied antipsychotics drugs indicate that these drugs do not cross the placental barrier. (iii) ADMET studies indicate that all the natural compounds are well tolerated by human body.

The limitation of the current study is a lack of experimental data, the fact that TI values were taken from some other studies, and that there are no experimental pregnancy TI data available due to ethical reasons.

This study is another proof that natural compounds can be a viable alternative to classical antidepressants when treating neuropsychiatric disorders. They have fewer side effects and can be used on pregnant women.

\section{Acknowledgement}

This work was supported by a grant of the Romanian Ministry of Research and Innovation, CCCDIUEFISCDI, project number PN-III-P1-1.2-PCCDI2017-0728/2018, contract no 693/2018, within PNCDI III.

\section{References}

1. Avram S, Alexandrescu I, Puia A, Udrea AM, Mernea M, Mihailescu DF, Borcan LC, Aneuploidy-Inducing Mutations in Mitotic Checkpoint Protein hMad1Carboxi Terminal Domain Analyzed by SAR and Computational Mutagenesis. Curr Proteomics, 2017; 14: 254-260.

2. Biragyn A, Aliseychik M, Rogaev E, Potential importance of B cells in aging and aging-associated neurodegenerative diseases. Seminars in Immunopath., 2017; 39(3): 283-294.

3. Bymaster F, Comparative Affinity of Duloxetine and Venlafaxine for Serotonin and Norepinephrine Transporters in vitro and in vivo, Human Serotonin Receptor Subtypes, and Other Neuronal Receptors. Neuropsychopharmacology, 2001; 25(6): 871-880.

4. DrugBank. DrugBank. www.drugbank.ca/.

5. Fogarasi E, Croitoru MD, FülöpI, Faliboga L, Vlase L, Jung A, Hohmann J, Balabanova B, Ivanova- 
Petropulos V, Mitrev S, Muntean DL, Chemical Properties of Several Red Wines Available on Romanian and Also on the International Market. Farmacia, 2018; 66(2): 309-315.

6. Gasteiger J, Marsili M, Iterative partial equalization of orbital electronegativity - a rapid access to atomic charges. Tetrahedron, 1980; 36(22): 3219-3228.

7. Ge JF, Xu YY, Qin G, Cheng JQ, Resveratrol Ameliorates the Anxiety- and Depression-Like Behavior of Subclinical Hypothyroidism Rat: Possible Involvement of the HPT Axis, HPA Axis, and Wnt/ $\beta$-Catenin Pathway. Front Endocrinol (Lausanne), 2016; 7(Art. 44): 1-14.

8. Gillman PK, Tricyclic antidepressant pharmacology and therapeutic drug interactions updated. $\mathrm{Br} J$ Pharmacol., 2007; 151(6): 737-748.

9. Grote NK, Bridge JA, Gavin AR, Melville JL, Iyengar S, Katon WJ, A Meta-analysis of Depression During Pregnancy and the Risk of Preterm Birth, Low Birth Weight, and Intrauterine Growth Restriction. Arch Gen Psychiatry, 2010; 67(10): 1012-1024.

10. Hewitt M, Madden JC, Rowe PH, Cronin MTD, Structure-based modelling in reproductive toxicology: (Q)SARs for the placental barrier. SAR QSAR Environ Res., 2007; 18(1-2): 57-76.

11. Hollon SD, Derubeis RJ, Fawcett J, Amsterdam JD, Shelton RC, Zajecka J, Young PR, Gallop R, Effect of Cognitive Therapy With Antidepressant Medications vs Antidepressants Alone on the Rate of Recovery in Major Depressive Disorder. JAMA Psychiatry, 2014; 71(10): 1157-1164.

12. Kasper S, Gastpar M, Müller WE, Volz HP, Möller HJ, Schläfke S, Dienel A, Lavender oil preparation Silexan is effective in generalized anxiety disorder - a randomized, double-blind comparison to placebo and paroxetine. Int J Neuropsychopharmacol., 2014; 17(06): 859-869.

13. Kent JM, SNaRIs, NaSSAs, and NaRIs: new agents for the treatment of depression. Lancet, 2000; 355(9207): 911-918.

14. Latruffe N, Natural Products and Inflammation. Molecules, 2017; 22(1): 120: 1-3.

15. Linde K, Kriston L, Rucker G, Jamil S, Schumann I, Meissner K, Sigterman K, Schneider A, Efficacy and Acceptability of Pharmacological Treatments for Depressive Disorders in Primary Care: Systematic Review and Network Meta-Analysis. Ann Fam Med., 2015; 13(1): 69-79.

16. Lipinski CA, Lombardo F, Dominy BW, Feeney $\mathrm{PJ}$, Experimental and computational approaches to estimate solubility and permeability in drug discovery and development settings. Adv Drug Deliv Rev., 2001; 46(1-3): 3-26.

17. Madhyastha S, Sekhar S, Rao G, Resveratrol improves postnatal hippocampal neurogenesis and brain derived neurotrophic factor in prenatally stressed rats. Int $J$ Dev Neurosci., 2013; 31(7): 580-585.

18. Marcus SM, Depression during Pregnancy: rates, Risks and Consequences. J Popul Ther Clin Pharmacol., 2009; 16(1): 15-22.

19. Molecular Operating Environment (MOE), 2010.10 (2010) by Chemical Computing Group Inc.

20. Oprea TI, Waller CL, Boyd DB, Lipkowitz KB, Theoretical and practical aspects of three-dimensional quantitative structure-activity relationships: Reviews in Computational Chemistry; Eds.; Wiley-VCH: New York, NY, USA, 2007; Vol. 11: 127-182.

21. PDSP. www.pdsp.unc.edu/databases/kidb.php.

22. Pires DEV Blundell TL, Asche DB, pkCSM: Predicting Small-Molecule Pharmacokinetic and Toxicity Properties Using Graph-Based Signatures. J Med Chem., 2015; 58: 4066-4072.

23. PkCSM-pharmacokinetics. www.biosig.unimelb.edu. au/pkcsm/.

24. Reiter RJ, Tan DX, Galano A, Melatonin: Exceeding Expectations. Physiology, 2014; 29(5): 325-333.

25. Tamura H, Nakamura Y, Terron M, Flores L, Tan D, Sugino N, Reiter R, Melatonin and pregnancy in the human. Reproductive Toxicology, 2008; 25(3): 291-303.

26. Team EBIW, ChEMBL. www.ebi.ac.uk/chembl/.

27. The PubChem Project. National Center for Biotechnology Information. PubChem Compound Database. www.pubchem.ncbi.nlm.nih.gov/.

28. Udrea AM, Puia A, Mernea M, Alexandrescu I, Avram S, Fast computational chemistry methods applied to new anti-Ebola virus entry drugs - application for new therapeutic targets. New Front Chem., 2017; 1: 1-10.

29. Vendrely VCA, Peuchant E, Buscail E, Moranvillier I, Rousseau B, Bedel A, Brillac A, Verneuil HD, MoreauGaudry F, Dabernat S, Resveratrol and capsaicin used together as food complements reduce tumor growth and rescue full efficiency of low dose gemcitabine in a pancreatic cancer model. Cancer Lett., 2017; 390: 91-102.

30. Wisner KL, Sit DK, Hanusa BH, Moses-Kolko EL, Bogen DL, Hunker DF, Perel JM, Jones-Ivy S, Bodnar LM, Singer LT, Major depression and antidepressant treatment: Impact on pregnancy and neonatal outcomes. Am J Psychiatry, 2009; 166(5): 557-566.

31. Yonkers KA, Lockwood CJ, Wisner K, The management of depression during pregnancy: a report from the American Psychiatric Association and the American College of Obstetricians and Gynecologists. Obstet Gynecol., 2009; 114(3): 703-713.

32. Zhang Y, Zhang L, Shi H, Sun J, Gaoi S, Li K, Efficacy of Paroxetine and Mirtazapine on Sleep in Patients with Depression and their Relationship with Polysomnography. Farmacia, 2018; 66(1): 157-164. 